\title{
Distribution of Adipose Tissue in the Newborn
}

\author{
TRACEY A.M. HARRINGTON, ELIZABETH LOUISE THOMAS, GARY FROST, \\ NEENA MODI, AND JIMMY D. BELL \\ The Robert Steiner MR Unit, MRC Clinical Sciences Centre [T.A.M.H., E.L.T., J.D.B.], Division of \\ Paediatrics, Obstetrics, and Gynaecology, Faculty of Medicine, Imperial College [T.A.M.H., N.M.], \\ Department of Nutrition and Dietetics, Hammersmith Hospital [G.F.], London W12 ONN, United Kingdom
}

\begin{abstract}
ABST
Regional differences in adipose tissue distribution are associ-
ated with differences in adipocyte metabolism and obesity-
related morbidities. Intrauterine growth restriction appears to
place individuals at greater risk of obesity associated morbidities
in later life. Despite this, little is known regarding the quantity
and distribution of adipose tissue in infants during early devel-
opment. The aim of this study was to compare total and regional
adipose tissue content in appropriate-for-gestational-age (AGA)
and growth-restricted (GR) newborn infants born at or near term.
Whole body adipose tissue magnetic resonance imaging (MRI)
was performed as soon as possible after birth. Total and regional
adipose tissue depots were quantified. A total of 35 infants (10
GR; 25 AGA) were studied. Mean (SD) total percentage adipose
tissue was lower in GR infants than AGA infants [GR: 17.70\%
(2.17); AGA: $23.40 \%$ (3.85); $p=0.003]$ This difference arose
from differences in subcutaneous adipose tissue mass [mean (SD)
\end{abstract}
percentage subcutaneous adipose tissue mass, GR: $16.13 \%$ (2.20); AGA: $21.44 \%$ (3.81); $p=0.004]$, but not intra-abdominal adipose tissue mass [mean (SD) percentage intra-abdominal adipose tissue, GR: $0.42 \%(0.22)$; AGA: $0.61 \%(0.31) ; p=$ $0.45]$. In contrast to subcutaneous adipose tissue, intra-abdominal adipose tissue is not reduced in infants with intrauterine growth restriction. This suggests that subcutaneous and intra-abdominal adipose tissue compartments may be under different regulatory control during intrauterine life. (Pediatr Res 55: 437-441, 2004)

$\quad$ Abbreviations
AGA, appropriate for gestational age
AT, adipose tissue
GR, growth restricted
DEXA, dual-energy x-ray absorptiometry
MRI, magnetic resonance imaging

Epidemiologic evidence suggests that poor growth in utero is a risk factor for the later development of insulin resistance and type-II diabetes (1). These conditions are strongly associated with obesity and, in particular, intra-abdominal obesity. Many of the studies that have examined this hypothesis have suggested that small size at birth is a marker of the fetal adaptations that program for these diseases later in life. However, the stage of growth during which the detrimental effects of growth restriction are established is not known. There is a paucity of information regarding the general effects of intrauterine growth restriction on adipose tissue distribution at birth, and changes in total and regional content during the first few months of postnatal growth.

Previous studies of body composition in AGA and GR infants have largely relied on indirect methodology to estimate adipose tissue content and are unable to provide information

Received November 25, 2002; accepted September 25, 2003.

Correspondence: Neena Modi, M.D., Division of Paediatrics, Obstetrics and Gynaecology, Faculty of Medicine, Imperial College, Chelsea and Westminster Hospital, 369 Fulham Rd., London SW10 9NH, U.K.: e-mail: n.modi@imperial.ac.uk

Supported by the Medical Research Council and Serono UK.

DOI: 10.1203/01.PDR.0000111202.29433.2D

about specific adipose tissue depots, particularly intraabdominal adipose tissue.

We, and others, have shown that MRI can be used in the direct assessment of adipose tissue content and distribution in neonates $(2,3)$. The technique has been validated in animals and cadavers and can be readily used in longitudinal measurements (4-7).

In the present study, we have compared the content and distribution of adipose tissue at birth in infants born at or near term, with an appropriate birth weight for gestational age, with that of infants with intrauterine growth restriction.

\section{METHODS}

Mothers undergoing investigation for fetal growth restriction were initially approached during the antenatal period to explain the study. Consent to recruit their infant into the study was formally obtained after delivery. Details of antenatal growth assessments were documented. Infants were classified as either AGA or GR if they had evidence of deceleration in growth in utero, together with clinical signs at birth suggestive of fetal malnutrition (loose thin skin with prominent ribs, a scaphoid abdomen, and muscle wasting over the cheeks, arms, buttocks, and thighs) and had a birth weight at or below the $9^{\text {th }}$ centile 
(8). Mothers were asked whether they had any dietary restrictions and data were obtained on racial group (Caucasian, African, Asian, mixed) and infant gender. The study was approved by the Hammersmith Hospitals Trust and Imperial College Faculty of Medicine Research Ethics Committee. Written informed parental consent was obtained.

\section{MRI}

Subjects were imaged in a 1.5-T Marconi Medical System Eclipse scanner as previously described $(3,7)$. No sedation was used and infants were positioned supine during natural sleep. We used a $T_{1}$-weighted spin-echo image sequence, with repetition time $(\mathrm{TR})=600 \mathrm{~ms}$, echo time $(\mathrm{TE})=16 \mathrm{~ms}$, field of view $=24 \mathrm{~cm}$, number of signal averages $=2$, and a $256 \times$ 256 matrix with phase conjugate symmetry. Images were analyzed as previously described $(3,7)$ using an image segmentation program that employs a threshold range and a contour-following algorithm with an interactive image-editing facility.

The initial analysis of MRI data results in the expression of adipose tissue content as volume of adipose tissue. This value may be converted to adipose tissue mass on the assumption that the density of adipose tissue is $0.9 \mathrm{~g} / \mathrm{cm}^{3}(5)$. Therefore, adipose tissue volume $\left(\mathrm{cm}^{3}\right) \times 0.9=$ adipose tissue mass $(\mathrm{g})$. Adipose tissue mass may be converted to lipid (fat) mass, assuming that $1 \mathrm{~g}$ of adipose tissue contains approximately $0.45 \mathrm{~g}$ lipid (9). Therefore, adipose tissue mass $(\mathrm{g}) \times 0.45=$ lipid mass (g).

Data in this article are expressed as adipose tissue mass, because the adipose tissue lipid content may not be the same in GR and AGA infants, nor the same in infants as in adults. We have expressed our data as lipid (fat) mass only where necessary for comparison with other published data,

Total adipose tissue was separated into total subcutaneous adipose tissue and total internal adipose tissue. Total subcutaneous adipose tissue was subdivided into abdominal subcutaneous and nonabdominal subcutaneous adipose tissue. Total internal adipose tissue was subdivided into intra-abdominal internal and nonabdominal internal adipose tissue. Abdominal adipose tissue content was obtained by quantifying adipose tissue in the slices from the top of the sacrum to the slice containing the top of the liver or base of the lungs (3). Subcutaneous adipose tissue in this region of the body was termed abdominal subcutaneous adipose tissue. Internal adipose tissue in the region was termed intra-abdominal internal adipose tissue. All other internal adipose tissue was termed nonabdominal internal. This includes, for example, adipose tissue between muscle planes and in bone marrow.

\section{ANTHROPOMETRY}

Weight (g), length $(\mathrm{cm})$, and head circumferences $(\mathrm{cm})$ were recorded at each examination by a single trained observer (TAMH). Each infant was weighed naked on an electronic scale (Marsden Professional Baby Scale; precision $\pm 2 \mathrm{~g}$ ). Crown-heel length was measured on a recumbent infant board with a sliding footboard (Rollametre: Raven Equipment Ltd., Dunmow, Essex, U.K.). Head circumference was measured using a plastic tape measure, taking the mean of three measurements (Child Growth Foundation tape measure). Ponderal index was calculated as [birth weight $(\mathrm{g}) \div$ length $\left.^{3}(\mathrm{~cm})\right] \times 100$.

\section{STATISTICAL ANALYSIS}

Results are presented as mean and SD. Multiple regression analysis was used to compare the AGA and GR groups after adjusting for gender, postmenstrual age at the time of imaging, racial group, and whether the mother had any dietary restrictions. In view of the relatively small number of infants, these variables were selected for inclusion in the multiple regression model based on knowledge of the relevant literature and not on internal study evidence. In addition, residuals from the multiple regression model were tested for normality. The level of significance was set at 5\%. Data were analyzed using Stata (10).

\section{RESULTS}

Thirty-five singleton infants were recruited into this study. Infants were imaged as soon as possible after birth. There were 25 AGA infants (14 male, 11 female) and 10 GR infants (5 male, 5 female). The mean (SD) age at imaging was 1.9 (1.8) d.

There were 20 Caucasian, 8 African/Afro-Caribbean, 2 Asian, and 8 mixed race infants. Four mothers excluded eggs, fish, and meat, but not dairy products, from their diet.

Although the infants were all born at or near term, the gestational age at birth of the GR infants was slightly but significantly less than that of the AGA infants [GR, 37.79 (1.11) wk; AGA, 39.16 (1.39) wk; $p=0.006$ ]. All subsequent multiple regression analyses were therefore performed allowing for postmenstrual age at time of imaging.

As anticipated, the length, weight, head circumference, and ponderal index of the GR infants were significantly smaller than the AGA infants (Table 1).

Absolute total adipose tissue mass and all subcutaneous compartments were significantly smaller in GR infants (Table 2) having allowed for postmenstrual age, gender, maternal dietary restriction, and race. There was no significant differ-

Table 1. Anthropometric data (mean, SD) in GR and AGA infants

\begin{tabular}{|c|c|c|c|c|c|}
\hline & $\begin{array}{c}\text { GR } \\
(n=10)\end{array}$ & $\begin{array}{c}\text { AGA } \\
(n=25)\end{array}$ & Coefficient & $95 \% \mathrm{CI}$ & $p$ Value \\
\hline Birth weight (kg) & $2.28(0.25)$ & $3.30(0.44)$ & -0.884 & -1.203 to -0.565 & $<0.001$ \\
\hline Length (cm) & $46.39(1.56)$ & $50.20(1.48)$ & -3.281 & -4.499 to -2.063 & $<0.001$ \\
\hline Head circumference $(\mathrm{cm})$ & $32.08(1.22)$ & $34.36(1.35)$ & -1.927 & -3.021 to -0.832 & 0.001 \\
\hline Ponderal index $\left(\mathrm{g} / \mathrm{cm}^{3}\right)$ & $2.29(0.25)$ & $2.61(0.31)$ & -0.281 & -0.529 to -0.032 & 0.028 \\
\hline
\end{tabular}

Coefficient and 95\% confidence interval (CI) estimating mean difference (GR-AGA) from multiple regression analysis allowing for gestational age. 
Table 2. Mean (SD) absolute adipose tissue content $(\mathrm{kg})$ in $G R$ and AGA infants

\begin{tabular}{lcccc}
\hline & $\begin{array}{c}\text { GR } \\
(n=10)\end{array}$ & $\begin{array}{c}\text { AGA } \\
(n=25)\end{array}$ & Coefficient & \multicolumn{1}{c}{$p$} \\
\hline Total & $0.398(0.071)$ & $0.757(0.219)$ & -0.315 & -0.505 to -0.125 \\
Total internal & $0.035(0.010)$ & $0.064(0.024)$ & -0.021 & -0.04 to 0.0009 \\
Total subcutaneous & $0.363(0.068)$ & $0.693(0.205)$ & -0.295 & -0.473 to -0.116 \\
Intra-abdominal & $0.010(0.005)$ & $0.020(0.011)$ & -0.006 & -0.016 to 0.0035 \\
Internal nonabdominal & $0.026(0.006)$ & $0.044(0.015)$ & -0.014 & -0.028 to -0.0006 \\
Subcutaneous abdominal & $0.045(0.011)$ & $0.100(0.041)$ & -0.045 & -0.080 \\
Subcutaneous nonabdominal & $0.317(0.059)$ & $0.593(0.168)$ & -0.250 & -0.396 to -0.009 \\
\hline
\end{tabular}

Coefficient and $95 \%$ confidence interval (CI) estimating mean difference (GR-AGA) from multiple regression analysis allowing for postmenstrual age, gender, race and maternal dietary restriction.

Table 3. Mean (SD) adipose tissue mass expressed as a percentage of body weight in GR and AGA infants

\begin{tabular}{lcccc}
\hline & $\begin{array}{c}\text { GR } \\
(n=10)\end{array}$ & $\begin{array}{c}\text { AGA } \\
(n=25)\end{array}$ & Coefficient & 95\% CI \\
\hline Total & $17.70(2.17)$ & $23.40(3.85)$ & -5.529 & -8.964 to -2.092 \\
Total internal & $1.56(0.39)$ & $1.96(0.58)$ & -0.257 & -0.805 to 0.291 \\
Total subcutaneous & $16.13(2.20)$ & $21.44(3.81)$ & -5.272 & -8.695 to -1.848 \\
Intra-abdominal & $0.42(0.22)$ & $0.61(0.31)$ & -0.108 & -0.397 to 0.181 \\
Internal nonabdominal & $1.14(0.24)$ & $1.35(0.34)$ & -0.149 & -0.476 to 0.179 \\
Subcutaneous abdominal & $2.03(0.48)$ & $3.07(0.84)$ & -0.854 & -1.623 to -0.085 \\
Subcutaneous nonabdominal & $14.10(1.80)$ & $18.37(3.17)$ & -4.418 & -7.221 to -1.615 \\
\hline
\end{tabular}

Coefficient and 95\% confidence interval (CI) estimating mean difference (GR-AGA) from multiple regression analysis allowing for postmenstrual age, gender, race and maternal dietary restriction.

ence between the groups in total internal and intra-abdominal internal adipose tissue content.

Similarly, when expressed as a percentage of body weight, total adipose tissue mass and all subcutaneous compartments were significantly smaller in the GR infants but there was no significant difference in internal adipose tissue compartments (Table 3).

Both Asian infants were GR. However, multiple regression analysis revealed no influence of race on adipose tissue compartments, nor was any influence of maternal dietary restriction identified. There were no significant differences in adipose tissue mass between male and female GR and AGA infants (total adipose tissue mass: GR male, $17.08 \%$ (2.90\%); GR female, $18.31 \%$ (1.12\%); AGA male, $22.76 \%$ (4.11\%); AGA female, $24.22 \%(3.51 \%)]$.

\section{DISCUSSION}

In adults and children, obesity is strongly associated with increased morbidity. A growing body of largely epidemiologic evidence, such as that from the Dutch famine cohort (11), suggests that intrauterine malnutrition is a risk factor for later obesity but the pathophysiological basis for this association is unknown. Although the Dutch famine cohort was exposed to extremes of maternal malnutrition and, as such, is different from the infants in our study, evidence from studies in other groups of infants in whom the etiology of poor intrauterine growth was unlikely to be due to maternal malnutrition have reported similar associations with later obesity (1). The infants in our study had the characteristic phenotype of compromised nutrition, namely loose, thin skin with prominent ribs, a scaphoid abdomen, and muscle wasting over the cheeks, arms, buttocks and thighs, and fetal malnutrition was due to preeclampsia and placental insufficiency and not to maternal malnutrition.

There appear to be depot-specific differences in the risks of adiposity-associated morbidity $(12,13)$, in keeping with depotspecific differences in the expression of genes coding for adipocyte proteins (14). Insulin resistance appears more powerfully related to increased intra-abdominal adipose tissue mass than to subcutaneous tissue mass. Conversely, generalized obesity and increased subcutaneous adipose tissue mass are associated with raised leptin levels $(13,15)$. Nonobese adults who had fetal malnutrition have been shown to have low serum leptin levels but higher intra-abdominal adipose tissue mass and greater insulin resistance than control subjects (16). Although these and similar observations have largely been made in adults, evidence is beginning to emerge that the distribution of adipose tissue is also a marker for morbidity in younger age groups. Intra-abdominal obesity has been shown to be associated with raised triglyceride levels in children (17). Whether the distribution of adipose tissue in infancy is also a marker for later morbidity is a question that will need to be addressed.

Using whole body adipose tissue MRI, we have confirmed previous observations of a reduction in total adipose tissue mass in GR infants. However, we have additionally made the novel observation that this difference arises because of a difference in subcutaneous adipose tissue but not intraabdominal adipose tissue. To ensure that we identified infants with evidence of intrauterine malnutrition as distinct from infants who were merely small at birth, we used a stringent set of criteria encompassing antenatal anthropometry and newborn phenotype together with a birth weight below the $10^{\text {th }}$ centile. 
Our findings support the conclusions of Gardeil et al. (18), who showed that reduced abdominal subcutaneous adipose tissue detected on antenatal ultrasonography is a predictor of growth restriction. In contrast to the highly significant difference in subcutaneous adipose tissue between the AGA and GR groups, we found no significant difference in intra-abdominal adipose tissue content, though we accept that our sample size was small. If confirmed in a larger sample size, this observation would suggest that subcutaneous adipose tissue and intraabdominal adipose tissue may be under different regulatory control during intrauterine life. Our data have added to the limited information on body composition in infancy. Fomon and Nelson (19) have reviewed the available evidence in updating their characterization of the "reference infant." Much of the data relating to fat and/or adipose tissue content in infancy is derived from indirect methods, principally DEXA, skinfold thickness, and total body electrical conductivity. These methods are unable to distinguish discrete adipose tissue deposits. Fat mass can also be estimated indirectly from the determination of lean body mass by methods such as total body potassium, total body water, total body impedance, and total body electrical conductivity. These methods are sensitive to the hydration factor of lean body mass and, as the error of estimation of fat mass is inversely related to fat mass, are inappropriate for use in preterm infants. Although widely used, the error of estimation of fat mass by DEXA also increases as fat mass decreases and has been reported to be $\pm 30 \%$ at a fat content of $100 \mathrm{~g} \mathrm{(20)}$.

The evidence relating to gender-specific differences in adiposity at birth are conflicting. We found no significant difference in percentage adipose tissue mass for AGA male and female infants at birth. We have also presented these data as lipid (fat) mass for comparison with other published data. Fomon et al. (21), in constructing their "reference" male and female infants, drew on body composition data from a variety of sources. They made the assumption that the ratio of fat to body weight is the same as the ratio of truncal skinfold thickness to body weight. They derived values for fat mass at birth of $13.7 \%$ for males and $14.9 \%$ for females. We estimated percentage lipid (fat) mass in AGA infants to be $10.2 \%$ in male infants and $10.9 \%$ in females. This estimate is similar to that of Butte et al. (22) (11.4\% males, $14.2 \%$ females), but less than the estimate of Rigo et al. (20) (15.7\%), derived from DEXA analyses. These differences may relate to differences in deriving fat mass from adipose tissue mass, the wide range of techniques used, and poor discrimination between AGA and GR infants. We calculated fat mass from adipose tissue mass assuming that $1 \mathrm{~g}$ of adipose tissue contains $0.45 \mathrm{~g}$ fat. This figure was based on the results of direct analysis of adipose tissue in biopsy specimens from nine term neonates (9). However, Kabir and Forsum (23) suggest that $1 \mathrm{~cm}^{3}$ of adipose tissue contains $0.66 \mathrm{~g}$ fat. They derived this estimate from direct analysis of adipose tissue in biopsy specimens from 38 infants. The use of these data would lead to an estimate of percentage lipid (fat) mass in the neonates in our study of AGA male $16.7 \%$ and AGA female 17.8\%. Fomon et al. (21) based their calculations on the assumption that adipose tissue contains $40 \%$ fat. Butte et al. (22) studied a total of 76 male and female infants from 0.5 mo to $2 \mathrm{y}$. They measured total body water by deuterium oxide dilution and estimated total body potassium ${ }^{40} \mathrm{~K}$ using a whole body counter. Using a multicomponent model based on a series of classical assumptions, they estimated percentage fat mass to be significantly higher in girls than boys at 6 and 9 mo of age but not at birth. The values that Butte et al. (22) derived for fat mass in male and female infants at birth are very similar to that of Owen et al. (24), who summarized data from whole body chemical analyses of six stillborn male infants, believed to have been born at term, and found that fat comprised $12 \%$ of body weight.

Genetic influences on adiposity are recognized. The Pima Indians, who have disproportionate levels of obesity and type-II diabetes in adult life, have been shown to gain excessive weight in infancy (25). Racial differences in adipose tissue distribution have been demonstrated in prepubertal children (26), but evidence to support the view that genetic differences are manifest at birth is lacking. Koo et al. (27) showed no effect of race on adipose tissue mass in normally grown or large for gestational age infants. We found no influence of race on adipose tissue distribution but we accept that our sample size was small. Equally, the power of our study was insufficient to detect any influence of differences in maternal dietary intake.

The postnatal growth trajectory appears to be a further influence on the risk of later obesity $(28,29)$. Observations in the ALSPAC (Avon Longitudinal Study of Pregnancy and Childhood) cohort show that children who experienced antenatal malnutrition and subsequent rapid catch-up growth were at greater risk of adiposity at the age of $5 \mathrm{y}$ than infants who maintained stable postnatal weight centiles (28). Currently accepted pediatric practice is to promote catch-up growth in infants with intrauterine growth restriction. Improved understanding of the determinants of differential adiposity may lead this view to be questioned. Our novel observation suggesting that the reduction in subcutaneous adipose tissue in GR infants at birth is not accompanied by a reduction in intra-abdominal adipose tissue suggests that there may be differences in the fetal programming of specific adipose tissue depots. To our knowledge, there have been no studies examining depotspecific alterations in adipose tissue during early postnatal growth. These will be essential to pave the way for focused nutritional or other interventions aimed at ameliorating the long-term consequences of intrauterine growth restriction.

Acknowledgments. The authors thank Caroline Doré, former Head, Statistical Consultancy Unit, Faculty of Medicine, Imperial College London, currently, Medical Research Council Clinical Trials Unit, London, for advice on statistical analysis. We also thank Professor Graeme Bydder, Dr. Mary Rutherford, Dr. Pam Johnson, and Dr. Glyn Coutts for their help, and the babies and their parents for participating in this study.

\section{REFERENCES}

1. Hales CN, Barker DJ 2001 The thrifty phenotype hypothesis. Br Med Bull 60:5-20

2. Olhager E, Thuomas KA, Wigstrom L, Forsum E 1998 Description and evaluation of a method based on magnetic resonance imaging to estimate adipose tissue volume and total body fat in infants. Pediatr Res 44:572-577 
3. Harrington TA, Thomas EL, Modi N, Frost G, Coutts GA, Bell JD 2002 Fast and reproducible method for the direct quantitation of adipose tissue in newborn infants. Lipids 37:95-100

4. Fowler PA, Fuller MF, Glasbey CA, Cameron GG, Foster MA 1992 Validation of the in vivo measurement of adipose tissue by magnetic resonance imaging of lean and obese pigs. Am J Clin Nutr 56:7-13

5. Ross R, Léger L, Guardo R, De Guise J, Pike BG 1991 Adipose tissue volume measured by magnetic resonance imaging and computerized tomography in rats. J Appl Physiol 70:2164-2172

6. Abate N, Burns D, Peshock RM, Garg A, Grundy SM 1994 Estimation of adipose tissue mass by magnetic resonance imaging: validation against dissection in human cadavers. J Lipid Res 35:1490-1496

7. Thomas EL, Saeed N, Hajnal JV, Brynes AE, Goldstone AP, Frost G, Bell JD 1998 Magnetic resonance imaging of total body fat. J Appl Physiol 85:1778-1785

8. The British 1990 Growth Reference (revised 1996). Child Growth Foundation, London

9. Baker GL 1969 Human adipose tissue and age. Am J Clin Nutr 22:829-835

10. StataCorp 2001 Stata Statistical Software: Release 7.0. Stata Corporation, College Station, TX

11. Ravelli GP, Stein ZA, Susser MW 1976 Obesity in young men after famine exposure in utero and early infancy. N Engl J Med 295:349-353

12. Ozanne SE, Dorling MW, Wang CL, Petry CJ 2000 Depot-specific effects of early growth retardation on adipocyte insulin action. Horm Metab Res 32:71-75

13. Cnop M, Landchild MJ, Vidal J, Havel PJ, Knowles NG, Carr DR, Wang F, Hull RL, Boyko EJ, Retzlaff BM, Walden CE, Knopp RH, Kahn SE 2002 The concurren accumulation of intraabdomial and subcutaneous fat explains the association between insulin resistance and plasma leptin concentrations: distinct metabolic effects of two fat compartments. Diabetes 51:1005-1015

14. Vidal H 2001 Gene expression in visceral and subcutaneous adipose tissues. Ann Med 33:547-555

15. Goldstone AP, Brynes AE, Thomas EL, Bell JD, Frost G, Holland A, Ghatei MA, Bloom SR 2002 Resting metabolic rate, plasma leptin concentrations, leptin receptor expression, and adipose tissue measured by whole-body magnetic resonance imaging in women with Prader-Willi syndrome. Am J Clin Nutr 75:468-475
16. Jaquet D, Gaboriau A, Czernichow P, Levy-Marchal C 2001 Relatively low serum leptin levels in adults born with intrauterine growth retardation. Int J Obes Relat Metab Disord 25:491-495

17. Cowin I, Emmett P 2000 Cholesterol and triglyceride concentrations, birthweight and central obesity in pre-school children. Int J Obes Relat Metab Disord 24:330-339

18. Gardeil F, Greene R, Stuart B, Turner MJ 1999 Subcutaneous fat in the fetal abdomen as a predictor of growth restriction. Obstet Gynecol 94:209-212

19. Fomon SJ, Nelson SE 2002 Body composition of the male and female reference infants. Ann Rev Nutr 22:1-17

20. Rigo J, Nyamugabo K, Picaud JC, Gerard P, Pieltain C, De Curtis M 1998 Reference values of body composition obtained by dual energy X-ray absorptiometry in preterm and term neonates. J Pediatr Gastroenterol Nutr 27:184-190

21. Fomon SJ, Haschke F, Ziegler EE, Nelson SE 1982 Body composition of reference children from birth to age 10 years. Am J Clin Nutr 35:1169-1175

22. Butte NF, Hopkinson JM, Wong WW, Smith EO, Ellis KJ 2000 Body composition during the first 2 years of life: an updated reference. Pediatr Res 47:578-585

23. Kabir N, Forsum E 1993 Estimation of total body fat and subcutaneous adipose tissue in full-term infants less than 3 months old. Pediatr Res 34:448-454

24. Owen GM, Filer LJ Jr, Maresh M, Fomon SJ 1966 Body composition of the infant Part II. Sex related differences in body composition in infancy. In: Falkner F (ed) Human Development. WB Saunders, Philadelphia, pp 246-253

25. Lindsay RS, Cook V, Hanson RL, Salbe AD, Tataranni A, Knowler WC 2002 Early excess weight gain of children in the Pima Indian population. Pediatrics 109:E33

26. He Q, Horlick M, Thornton J, Wang J, Pierson RN Jr, Heska S, Gallagher D 2002 Sex and race differences in fat distribution among Asian, African-American and Caucasian prepubertal children. J Clin Endocrinol Metab 87:2164-2170

27. Koo WW, Walters JC, Hockman EM 2000 Body composition in human infants at birth and postnatally. J Nutr 130:2188-2194

28. Ong KL, Ahmed ML, Emmett PM, Preece MA, Dunger DB 2000 Association between postnatal catch-up growth and obesity in childhood: prospective cohort study. BMJ 320:967-971

29. Tanaka T, Matsuzaki A, Kuromaru R, Kinukawa N, Nose Y, Matsumoto T, Hara T 2001 Association between birthweight and body mass index at 3 years of age. Pediatr Int 43:641-646 